\title{
CARACTERÍSTICAS DE CARCAÇA E RECEITA INDUSTRIAL COM CORTES PRIMÁRIOS DA CARCAÇA DE MACHOS NELORE ABATIDOS COM DIFERENTES PESOS
}

\author{
FABIANO Nunes VAZ ${ }^{1}$, JoÃo RESTLE ${ }^{2}$, JoÃo TEOdORO PÁdUA ${ }^{3}$, CRISTIANE AMORIM FonseCA ${ }^{4}$, \\ PAUlO SANTANA PACHECO ${ }^{1}$ \\ ${ }^{1}$ Professores Doutores da Universidade Federal de Santa Maria, Santa Maria, RS, Brasil. \\ fabianonunesvaz@gmail.com \\ ${ }^{2}$ Professor Visitante Nacional Senior (CAPES) na Universidade Federal do Tocantins, Araguaína, TO, Brasil \\ ${ }^{3}$ Professor Doutor da Universidade Federal de Goiás, Goiânia, GO, Brasil \\ ${ }^{4}$ Pós-Graduanda em Ciência Animal na Universidade Federal de Goiás, Goiânia, GO, Brasil
}

RESUMO

\begin{abstract}
O objetivo deste trabalho foi avaliar a receita dos cortes comerciais e estudar as características de carcaça de machos Nelore não castrados abatidos com diferentes pesos. Foram utilizados 40 machos Nelore com peso médio inicial de $350 \mathrm{~kg}$. Os animais foram divididos em quatro grupos: animais com zero e dois dentes, com peso de carcaça de até 238,0 kg (jovens e carcaças leves); animais com dois dentes com peso de carcaça variando de 238,1 a 258,0 kg (jovens e carcaças médias); animais com dois dentes com peso de carcaça superior a 258,0 kg (jovens e carcaças pesadas) e animais com quatro ou seis dentes, independente do peso de carcaça (adultos). Depois
\end{abstract}

de 84 dias de confinamento, os animais foram enviados para abate em estabelecimento comercial. Não se verificou diferença nas variáveis de gordura da carcaça e marmoreio da carne, bem como das percentagens dos cortes comerciais da carcaça, no peso e no rendimento de carcaça quente. A análise de receitas mostrou que, em função das diferenças de preço no atacado dos cortes primários da carcaça, os trabalhos de melhoramento em bovinos deveriam procurar o aumento da conformação e percentuais de traseiro especial, desde que atendidos os graus de acabamento mínimos exigidos pelos frigoríficos.

PALAVRAS-CHAVE: bovinos não castrados; cortes comerciais; grau de acabamento; peso de abate; ponto de equilíbrio industrial.

\section{CARCASS CHARACTERISTICS AND INDUSTRIAL INCOME WITH CARCASS PRIMARY CUTS OF NELLORE MALES SLAUGHTERED AT DIFFERENT WEIGHTS}

\section{ABSTRACT}

The objective of this study was to evaluate the commercial cuts income and to study the carcass characteristics of non-castrated Nellore males slaughtered at different weights. Forty Nellore males with initial average weight of $350 \mathrm{~kg}$ were used. The animals were divided into four groups: animals with 0 and two teeth, with carcass weight up to238,0 kg (young and light carcass); 2-teeth animals with carcass weight ranging from 238,1 to $258,0 \mathrm{~kg}$ (young and medium carcass); 2-teeth animals with carcass weight above $258 \mathrm{~kg}$ (young and heavy carcass) and animals with four or six teeth, regardless of carcass weight (adults). After 84 days of feedlot, the animals were slaughtered in a commercial abattoir. There was no difference for carcass fat characteristics and meat marbling, as well as for commercial cuts percentages, hot carcass weight and yield. Income analysis showed that, depending on the wholesale price differences of the primary cuts of the carcass, studies on cattle breeding should seek to increase the conformation and hindquarter percentage, provided they meet the minimum finishing degree required by the abattoirs.

KEYWORDS: commercial cuts; fatness level; industrial break-even point; non-castrated males; slaughter weight. 


\section{INTRODUÇÃO}

Os incrementos de produtividade da bovinocultura de corte passam pela redução da idade de abate, a qual representa um aspecto importante para a eficiência da organização rural como empresa e para a pecuária brasileira como um todo (RODRIGUES et al., 2007). Entretanto, a redução da idade de abate somente é viável se os novilhos atingirem peso adequado e grau de acabamento que atenda às exigências dos frigoríficos. Nesse contexto, o contraponto estabelecido na pecuária de ciclo curto está relacionado ao peso de abate que os animais precisam atingir para serem comercializados (CAMARGO et al., 2008), pois, dos cinco níveis de terminação estabelecidos pelo sistema brasileiro de tipificação de carcaças (BRASIL, 2004), somente três são aceitos pelo mercado.

Além de importantes para o mercado e para os sistemas produtivos, o peso de abate e o acabamento são considerados os fatores principais para determinar a qualidade da carne. No entanto, tais fatores são influenciados pela pressão comercial dos frigoríficos que exigem animais pesados, privilegiando animais com maturidade mais avançada, e o avanço da idade reduz a maciez da carne.

Atualmente os produtores já compreendem que a economicidade do processo de terminação é uma relação entre custo da alimentação, preço de aquisição do animal magro e preço de venda do animal gordo, multiplicado pelo seu peso de abate que, por sua vez, depende da qualidade da dieta (SIGNORETTI et al., 2008). Assim, é interessante para os produtores reduzirem ao máximo o período de terminação dos animais quando a relação de troca entre boi gordo e boi magro for alta e viceversa.

KUSS et al. (2009) estudaram animais mestiços Purunã e Canchim estabelecendo similaridade no rendimento de carcaça de animais superjovens, com 16 meses ao abate $(57,9 \%)$, e jovens, com 26 meses ao abate $(57,5 \%)$. Em contraposição, PACHECO et al. (2005), estudando mestiços Charolês e Nelore, afirmaram que, embora os rendimentos de carcaça quente e de carcaça fria tenham sido similares entre superjovens e jovens, houve diferença nos percentuais de ponta-de-agulha e traseiro especial entre os dois grupos. No trabalho em questão, os animais mais erados apresentaram menor percentagem de ponta-de-agulha e maior percentual de traseiro especial, mas, com o mesmo peso de abate estipulado para as duas categorias, não houve diferenças no peso dos três cortes comerciais primários da carcaça.
Direcionada à indústria frigorífica, a pesquisa em Zootecnia ainda não conseguiu determinar bases de resultados científicos que identifiquem as implicações que um processo de terminação mais rápido e consequente menor peso de carcaça trazem para a rentabilidade da empresa. Em um trabalho inovador para a pesquisa brasileira, PASCOAL et al. (2011) afirmaram que o ponto de equilíbrio da atividade frigorífica passa pela composição de custos industriais, aquisição do boi gordo e os preços obtidos com a venda dos componentes não-carcaça e dos cortes comestíveis. Assim, a partir de dados referenciais de preços de mercado, o objetivo deste trabalho é realizar uma avaliação econômica do abate e estudar as características de carcaça de machos Nelore jovens, não castrados, abatidos com diferentes pesos, comparando-os com animais com maturidade mais avançada.

\section{MATERIAL E MÉTODOS}

Este trabalho foi realizado em dois estados. A terminação dos animais foi realizada em propriedade privada, no estado de Goiás, assim como o abate, em frigorífico comercial no mesmo estado, conduzidos por pesquisadores da Universidade Federal de Goiás e Universidade Federal de Tocantins. As análises econômica e estatística foram realizadas no estado do Rio Grande do Sul, por pesquisadores da Universidade Federal de Santa Maria e da Universidade Federal do Pampa, campus Dom Pedrito.

Foram utilizados 40 machos Nelore não castrados, com peso médio no início do confinamento de $350 \mathrm{~kg}$, criados na referida fazenda, com manejo sanitário e nutricional similares nos seis meses que antecederam o início do confinamento. Os animais foram divididos em quatro grupos: animais com zero e dois dentes, com peso de carcaça de até $238,0 \mathrm{~kg}$ (jovens e carcaças leves); animais com dois dentes com peso de carcaça variando de 238,1 a 258,0 kg (jovens e carcaças médias); animais com dois dentes com peso de carcaça superior a $258,0 \mathrm{~kg}$ (jovens e carcaças pesadas) e animais com quatro ou seis dentes, independente do peso de carcaça (adultos).

A terminação dos animais foi desenvolvida durante o período de 26/07 a 03/11, oferecendo-se aos animais uma dieta contendo $60 \%$ de silagem de milho como volumoso e $40 \%$ de concentrado à base de milho moído, farelo de trigo, farelo de soja e minerais. A dieta continha 11,87\% de proteína bruta e $68,29 \%$ de NDT, calculada objetivando-se um ganho de peso médio de $1,2 \mathrm{~kg} / \mathrm{dia}$.

Antes do embarque, o estado corporal 
subjetivo dos animaisfoi avaliado por meio de três avaliadores que utilizaram o escore em escala de 1 a 5 pontos: 1 = muito magro; $2=$ magro; $3=$ mediano; $4=$ gordo; $5=$ muito gordo. $\mathrm{Na}$ sequência, os animais foram pesados após jejum de sólidos de 14 horas e embarcados para um abatedouro comercial. O abate dos bovinos foi realizado em um único dia, em estabelecimento com Serviço de Inspeção Federal (SIF).

Após o abate, foi conferida a dentição e feita a classificação e tipificação das carcaças dos animais, conforme a Portaria N. 612 do Ministério da Agricultura, Pecuária e Abastecimento (BRASIL, 2004). Em seguida, as carcaças foram identificadas, lavadas, divididas em metades iguais, pesadas e levadas ao resfriamento por 24 horas à temperatura de $1^{\circ} \mathrm{C}$ a $-2^{\circ} \mathrm{C}$. Decorrido esse tempo, as meia-carcaças foram retiradas da câmara fria, novamente pesadas e encaminhadas para uma sala refrigerada onde foram realizadas as avaliações de maturidade fisiológica, espessura de gordura de cobertura na altura da $12^{\mathrm{a}}$ costela e medida de comprimento de carcaça, conforme método sugerido por MÜLLER (1987).

$\mathrm{Na}$ sequência, as meia-carcaças direitas foram destinadas para avaliações das características organolépticas da carne. $\mathrm{Na}$ altura da $12^{\mathrm{a}}$ costela, o músculo longissimus dorsi foi seccionado transversalmente e, após exposição ao ar por 20 minutos, foram avaliadas subjetivamente as características de cor, textura e marmoreio, conforme escalas sugeridas por MÜLLER (1987).

Para determinação da composição física da carcaça em músculo, gordura e osso foi extraída uma peça correspondendo às $10-11-12^{\mathrm{a}}$ costelas da meia-carcaça direita, segundo a metodologia proposta por Hankins \& Howe (1946), adaptada por MÜLLER (1973), em que: Músculo = 15,56 +
$0,81 * \mathrm{MHH}$; Gordura $=3,06+0,82 * \mathrm{GHH}$; Osso $=$ $4,30+0,61^{*} \mathrm{OHH}$; sendo $\mathrm{MHH}, \mathrm{GHH}$ e $\mathrm{OHH}$, músculo, gordura e osso, respectivamente.

As meias-carcaças esquerdas foram divididas nos três cortes comerciais: dianteiro, costilhar ou ponta-de-agulha e traseiro especial ou serrote. Essas porções foram pesadas e suas respectivas porcentagens em relação ao peso das meias-carcaças foram calculadas.

O delineamento experimental foi inteiramente casualizado, conforme $\mathrm{o}$ modelo estatístico: $Y_{i j}=\mu+\alpha_{i}+\varepsilon_{i j}$ sendo, $Y_{i j}$ o valor observado no i-ésimo grupo de animais, na j-ésima repetição; $\mu$ a média geral da variável; $\alpha_{\mathrm{i}} \mathrm{o}$ efeito do i-ésimo grupo de animais; e $\varepsilon_{\mathrm{ij}} \mathrm{o}$ efeito aleatório associado a cada observação.

Os dados foram submetidos à análise de variância pelo procedimento de Modelos Lineares Gerais (PROC GLM), suas médias ajustadas pelo método dos Quadrados Mínimos (LSMEANS) e comparadas pelo Teste de Tukey ao nível de significância de $5 \%$ de probabilidade de erro, utilizando-se o programa estatístico SAS (1999).

\section{RESULTADOS E DISCUSSÃO}

$\mathrm{O}$ peso de abate (Tabela 1) dos animais adultos foi intermediário $(471 \mathrm{~kg})$ e similar $(\mathrm{P}>0,05)$ aos animais dos grupos jovens com carcaças médias (448 kg) e com carcaças pesadas (495 kg). Similaridade também foi observada na característica peso de carcaça fria, mas o peso de carcaça quente diferiu dos animais adultos, que possuíam dentição de quatro e seis dentes $(264 \mathrm{~kg})$ em relação aos animais com dois dentes com carcaças médias $(249 \mathrm{~kg})$.

Tabela 1 - Peso de abate, de carcaça quente e de carcaça fria, quebra ao resfriamento e rendimento de carcaça quente de machos inteiros da raça Nelore abatidos com diferentes pesos e dentições

\begin{tabular}{lccccccc}
\hline Variável independente & $\begin{array}{c}\text { Jovens } \\
\text { leves }\end{array}$ & $\begin{array}{c}\text { Jovens } \\
\text { médios }\end{array}$ & $\begin{array}{c}\text { Jovens } \\
\text { pesados }\end{array}$ & $\begin{array}{c}\text { Adul- } \\
\text { tos }\end{array}$ & $\mathrm{R}^{2}$ & $\mathrm{CV}, \%$ & $\mathrm{P}>\mathrm{F}$ \\
\hline Número de animais & 12 & 9 & 10 & 9 & & & \\
Dentição média & 1,33 & 2,00 & 2,00 & 4,44 & & & \\
Peso de abate, kg & $421^{\mathrm{c}}$ & $448^{\mathrm{bc}}$ & $495^{\mathrm{a}}$ & $471^{\mathrm{ab}}$ & 0,59 & 5,39 & 0,001 \\
Peso de carcaça quente, kg & $230^{\mathrm{c}}$ & $249^{\mathrm{b}}$ & $273^{\mathrm{a}}$ & $264^{\mathrm{a}}$ & 0,65 & 5,13 & 0,001 \\
Peso de carcaça fria, kg & $225^{\mathrm{c}}$ & $243^{\mathrm{b}}$ & $266^{\mathrm{a}}$ & $258^{\mathrm{ab}}$ & 0,24 & 7,51 & 0,018 \\
Quebra ao resfriamento, \% & 2,22 & 2,47 & 2,63 & 2,32 & 0,26 & 9,56 & 0,190 \\
Rend. de carc. quente, $\%$ & 54,6 & 55,6 & 55,2 & 56,2 & 0,14 & 2,81 & 0,123 \\
\hline
\end{tabular}

${ }^{\mathrm{a}, \mathrm{b}, \mathrm{c}}$ na linha, na comparação entre grupos de animais, representa que as médias diferem $(\mathrm{P}<0,05)$ pelo Teste de Tukey. 
A quebra ao resfriamento das carcaças foi alta, em média $2,41 \%$, valor superior ao que é observado em pesquisas e admitido pela indústria frigorífica, que considera uma quebra normal próxima a 2\% (BUENO et al., 2000).

O maior peso de carcaça quente dos animais adultos é reflexo do rendimento de carcaça quente numericamente $(\mathrm{P}>0,05)$ superior destes em relação aos grupos de animais jovens, independente do agrupamento de pesos de carcaça. MC CURDY et al. (2010) constataram que o incremento no peso de abate melhora os rendimentos de carcaça quente e fria, quando expressos em relação ao peso de abate, mas observaram similaridade de rendimentos, quando estes são expressos em relação ao peso de corpo vazio.
Aumento do rendimento de carcaça em cordeiros mais velhos ao abate foi citado por BUENO et al. (2000), que afirmam que esse comportamento, apesar de ser favorável comercialmente, é devido ao maior acúmulo de gordura na carcaça dos animais com o aumento da idade. O peso total dos componentes externos, total de órgãos vitais, total de gordura interna e total do trato gastrintestinal vazio, em valores absolutos, aumenta com o incremento no peso de abate. Porém, quando ajustados para peso de abate e peso de corpo vazio, os pesos totais dos componentes externos e do trato gastrintestinal vazio apresentam similaridade, o total de órgãos vitais decresce e o total de gorduras internas se eleva com o aumento no peso de abate (JEREZ-TIMAURE \& HUERTA-LEIDENZ, 2009).

Tabela 2 - Características de carcaça de machos inteiros da raça Nelore abatidos com diferentes pesos e dentições

\begin{tabular}{|c|c|c|c|c|c|c|c|}
\hline Variável independente & $\begin{array}{c}\text { Jovens } \\
\text { leves }\end{array}$ & $\begin{array}{l}\text { Jovens } \\
\text { médios }\end{array}$ & $\begin{array}{c}\text { Jovens } \\
\text { pesados }\end{array}$ & Adultos & $\mathrm{R}^{2}$ & $\mathrm{CV}, \%$ & $\mathrm{P}>\mathrm{F}$ \\
\hline Número de animais & 12 & 9 & 10 & 9 & & & \\
\hline Dentição média & 1,33 & 2,00 & 2,00 & 4,44 & & & \\
\hline Escore corporal vivo ${ }^{c}$ & $3,62^{b}$ & $3,75^{\mathrm{ab}}$ & $3,84^{\mathrm{a}}$ & $3,78^{\mathrm{ab}}$ & 0,23 & 4,34 & 0,030 \\
\hline Espessura de gordura, mm & 3,24 & 3,79 & 3,87 & 3,74 & 0,12 & 20,26 & 0,189 \\
\hline Acabamento & 2,71 & 2,67 & 2,70 & 2,89 & 0,02 & 20,84 & 0,838 \\
\hline Comprimento de carcaça, cm & 131 & 135 & 134 & 132 & 0,14 & 3,14 & 0,462 \\
\hline Cor, pontos ${ }^{\mathrm{d}}$ & 3,10 & 3,55 & 3,42 & 3,26 & 0,03 & 29,15 & 0,736 \\
\hline Textura, pontos ${ }^{\mathrm{e}}$ & 3,63 & 3,50 & 3,83 & 4,02 & 0,08 & 18,75 & 0,411 \\
\hline Marmoreio, pontos ${ }^{\mathrm{f}}$ & 3,25 & 4,87 & 4,37 & 3,00 & 0,12 & 54,45 & 0,176 \\
\hline
\end{tabular}

Além dos componentes não-carcaça, a diferença significativa no rendimento de carcaça poderia ser atribuída às variações nos graus de acabamento das carcaças, fato que não aconteceu no presente trabalho, conforme pode ser constatado na Tabela 2. Esse resultado demonstra que os quatro grupos de animais estudados apresentavam acabamento adequado para o padrão de mercado brasileiro, evidenciado também pela avaliação subjetiva do acabamento conforme as normas do MAPA (BRASIL, 2004).

$\mathrm{Na}$ avaliação do estado corporal dos animais ainda vivos, em escala de 1 a 5, observou-se que os animais jovens e com carcaças leves apresentaram escore corporal inferior aos animais jovens e com carcaças pesadas $(\mathrm{P}>0,05)$. Os animais adultos e jovens com carcaças médias foram intermediários e semelhantes aos grupos de animais jovens com carcaças leves e jovens com carcaças pesadas. Ao se verificar que os animais adultos não diferiram de nenhum grupo de animais, ou seja, que houve similaridade entre animais adultos e os três grupos de carcaças de machos jovens $(\mathrm{P}>0,05)$ é necessário analisar a espessura de gordura medida na carcaça, melhor determinante do grau de acabamento das carcaças. Observa-se que a espessura de gordura variou de 3,24 a 3,87 mm nos animais jovens e foi de $3,74 \mathrm{~mm}$ nos animais adultos $(\mathrm{P}>0,05)$. Similaridade entre os grupos de carcaças também foi verificada na característica marmoreio de carcaça, que variou de 3,00 a 4,87 pontos, que seria classificado como "traços mais" e "leve típico". O pequeno grau de marmoreio se deve aos fatores raça e a não castração dos animais (RIBEIRO et al., 2002).

Em uma comparação com outros trabalhos que estudaram animais castrados, verificou-se coloração da carne variando de 3,10 a 3,55 (P>0,05), pode indicar que os animais foram submetidos a 
estresse que pode resultar em alta quebra ao resfriamento da carcaça. No presente estudo não foi medido o $\mathrm{pH}$ das carcaças, que poderia indicar carnes PSE (pálidas, suaves e exudativas).

ALBERTÍ et al. (2008) estudaram as características de carcaça de diferentes raças de bovinos de corte europeias, classificando-as em três grupos conforme as aptidões, por considerarem as diferenças no crescimento dos tecidos das carcaças dos animais, entre eles a gordura. Os autores citam as raças europeias, principalmente britânicas, como aquelas que possuem um longo processo de seleção para deposição de gordura na carcaça. Já na raça Nelore e nas raças europeias continentais, o processo de deposição de gordura é mais tardio (MARCONDES et al., 2012).

O comprimento de carcaça dos quatro grupos de animais foi similar $(\mathrm{P}>0,05)$, indicando que as diferenças de peso dos animais pode ser reflexo da maior relação porção comestível / osso das carcaças mais pesadas (SIGNORETTI et al., 1999). Na Tabela 3 , observa-se que os animais tiveram percentagens de músculo e de gordura similares, mas os animais adultos tiveram menor percentagem de osso que os bovinos jovens com carcaças pesando entre 238,1 e $258,0 \mathrm{~kg}(\mathrm{P}<0,05)$. A redução na percentagem de ossos com o avanço da idade é reflexo do aumento do grau de acabamento dos animais ou resultado de um processo de realimentação, no qual os animais possuem estrutura esquelética definida, mas, por restrição alimentar, os demais tecidos da carcaça foram reduzidos (ROBERTS et al., 2007). O fato de os animais Nelore não castrados, com quatro ou seis dentes, pesarem $264 \mathrm{~kg}$ de carcaça, é um indicativo de que alguns animais refletem algum período de restrição alimentar anterior.

Estudando diferentes níveis de concentrado na ração de bezerros de $190 \mathrm{~kg}$, SIGNORETTI et al. (1999) não observaram efeito de energia da dieta na proporção de ossos da carcaça, porém a percentagem de músculos diminuiu e a de gordura e as relações tecido adiposo / tecido ósseo e tecido adiposo / tecido muscular, aumentaram linearmente com o incremento da energia das rações. Já nos bezerros de $300 \mathrm{~kg}$, o aumento do nível energético da dieta aumentou apenas a relação tecido muscular / ossos da carcaça. Em função de os animais do presente estudo apresentarem estado corporal e espessura de gordura sobre a carcaça similares $(P>0,05)$, não é estranho as relações teciduais das carcaças serem também similares entre os quatro grupos analisados.

Não foi observada diferença nas percentagens de osso entre os animais jovens com diferentes pesos de carcaças. A menor percentagem de osso nos animais adultos não se refletiu nos percentuais dos cortes comerciais primários das carcaças (Tabela 4), sendo que os pesos dos cortes comerciais seguiram o comportamento observado para o peso de carcaça quente, apresentado na Tabela 1.

Estudando os pesos de abate 430, 470 e 530 $\mathrm{kg}$, MALDONADO et al. (2007) observaram similaridade nos percentuais de ponta de agulha e dianteiro, mas os animais mais leves apresentaram maior percentual de traseiro especial que os grupos com 470 e $530 \mathrm{~kg}$. Para os autores, diferenças de maior desenvolvimento das partes traseiras e dorsal podem ocorrer em animais mais jovens, o que não foi o caso do presente estudo.

As diferenças nos pesos dos cortes comerciais das carcaças (Tabela 4), juntamente com os pesos de carcaças (Tabela 1) e os preços praticados no mercado atacadista da Grande São Paulo (CEPEA, 2011) são as bases para a discussão da avaliação econômica do abate dos animais de diferentes pesos de carcaça e idades. Para isso, observa-se na Tabela 5 que, ao ser dividida a receita com a venda dos cortes pelo peso de carcaça de cada grupo, obtém-se o preço de equilíbrio para aquisição do animal gordo que pode ser pago pela indústria, se desconsideradas a receita com componentes nãocarcaça (PASCOAL et al., 2011) e diferenças no custo de industrialização em função de peso de carcaça.

Tabela 3 - Percentagem de músculo, gordura e osso na carcaça de machos inteiros da raça Nelore abatidos com diferentes pesos e dentições

\begin{tabular}{lccccccc}
\hline Variável independente & $\begin{array}{c}\text { Jovens } \\
\text { leves }\end{array}$ & $\begin{array}{c}\text { Jovens } \\
\text { médios }\end{array}$ & $\begin{array}{c}\text { Jovens } \\
\text { pesados }\end{array}$ & Adultos & $\mathrm{R}^{2}$ & $\mathrm{CV}, \%$ & $\mathrm{P}>\mathrm{F}$ \\
\hline Número de animais & 12 & 9 & 10 & 9 & & & \\
Dentição média & 1,33 & 2,00 & 2,00 & 4,44 & & & \\
Percentagem de músculo & 63,2 & 63,4 & 64,6 & 65,1 & 0,10 & 3,78 & 0,245 \\
Percentagem de gordura & 22,8 & 22,0 & 21,8 & 22,3 & 0,03 & 10,15 & 0,729 \\
Percentagem de osso & $14,8^{\text {ab }}$ & $15,2^{\mathrm{a}}$ & $14,5^{\text {ab }}$ & $13,9^{\mathrm{b}}$ & 0,26 & 5,77 & 0,010 \\
a,b & na linha, na comparação entre grupos de animais, representa que as médias diferem $(\mathrm{P}<0,05)$ pelo Teste de Tukey.
\end{tabular}


Tabela 4 - Pesos e percentagens dos cortes comerciais primários das carcaças de machos inteiros da raça Nelore abatidos com diferentes pesos e dentições

\begin{tabular}{lccccccc}
\hline Variável independente & $\begin{array}{c}\text { Jovens } \\
\text { leves }\end{array}$ & $\begin{array}{c}\text { Jovens } \\
\text { médios }\end{array}$ & $\begin{array}{c}\text { Jovens } \\
\text { pesados }\end{array}$ & Adultos & $\mathrm{R}^{2}$ & CV,\% & P>F \\
\hline Número de animais & 12 & 9 & 10 & 9 & & & \\
Dentição média & 1,33 & 2,00 & 2,00 & 4,44 & & & \\
Peso da ponta-de-agulha, $\mathrm{kg}$ & $13,6^{\mathrm{b}}$ & $14,6^{\mathrm{ab}}$ & $15,5^{\mathrm{a}}$ & $14,3^{\mathrm{ab}}$ & 0,18 & 10,52 & 0,056 \\
Percentagem de p. agulha & 11,7 & 11,7 & 11,9 & 11,6 & 0,02 & 5,72 & 0,793 \\
Peso do dianteiro, kg & $44,5^{\mathrm{b}}$ & $47,7^{\mathrm{ab}}$ & $50,3^{\mathrm{a}}$ & $47,4^{\mathrm{ab}}$ & 0,22 & 8,92 & 0,026 \\
Percentagem de dianteiro & 38,0 & 38,2 & 38,5 & 38,5 & 0,04 & 3,02 & 0,636 \\
Peso do traseiro especial, $\mathrm{kg}$ & $57,1^{\mathrm{b}}$ & $60,0^{\mathrm{ab}}$ & $61,6^{\mathrm{a}}$ & $57,9^{\mathrm{ab}}$ & 0,21 & 6,17 & 0,036 \\
Percentagem de tr. especial & 48,4 & 48,2 & 47,3 & 47,1 & 0,14 & 2,89 & 0,147 \\
\hline
\end{tabular}

${ }^{\mathrm{a}, \mathrm{b}}$ na linha, na comparação entre grupos de animais, representa que as médias diferem $(\mathrm{P}<0,05)$ pelo Teste de Tukey.

Tabela 5 - Determinação do preço do ponto de equilíbrio de compra de machos inteiros da raça Nelore abatidos com diferentes pesos e dentições, em função das receitas de vendas dos cortes primários das carcaças

\begin{tabular}{lccccc}
\hline Variável independente & $\begin{array}{c}\text { Jovens } \\
\text { leves }\end{array}$ & $\begin{array}{c}\text { Jovens } \\
\text { médios }\end{array}$ & $\begin{array}{c}\text { Jovens } \\
\text { pesados }\end{array}$ & Adultos & $\mathrm{R}^{\mathrm{a}}$ \\
\hline Número de animais & 12 & 9 & 10 & 9 & \\
Dentição média & 1,33 & 2,00 & 2,00 & 4,44 & \\
Peso da ponta-de-agulha, kg & 13,60 & 14,60 & 15,50 & 14,30 & 4,75 \\
Peso do dianteiro, kg & 44,50 & 47,70 & 50,30 & 47,70 & 4,95 \\
Peso do traseiro especial, kg & 57,10 & 60,00 & 61,60 & 57,90 & 7,28 \\
Venda de uma ponta-de-agulha, $\mathrm{R} \$$ & 64,60 & 69,35 & 73,63 & 67,93 & \\
Venda de um dianteiro, $\mathrm{R} \$$ & 220,28 & 236,12 & 248,99 & 236,12 & \\
Venda de um traseiro especial, $\mathrm{R} \$$ & 415,69 & 436,80 & 448,45 & 421,51 & \\
Venda de uma meia-carcaça, R $\$$ & 700,56 & 742,27 & 771,06 & 725,55 & \\
Venda de duas meia-carcaças, $\mathrm{R} \$$ & $1.401,13$ & $1.484,53$ & $1.542,12$ & $1.451,10$ & \\
Peso de carcaça quente, $\mathrm{kg}$ & 230 & 249 & 273 & 264 & \\
Peso de carcaça menos $2 \%, \mathrm{~kg}$ & 225 & 244 & 268 & 259 & \\
Equilíbrio de compra, $\mathrm{R} \$ \mathrm{~kg}$ carcaça & 6,22 & 6,08 & 5,76 & 5,61 & \\
Equilíbrio de compra, $\mathrm{R} \$$ /@ carcaça & 93,30 & 91,20 & 86,40 & 84,15 & \\
\hline
\end{tabular}

${ }^{a}$ Preço dos cortes comerciais por kg no atacado da Grande São Paulo (CEPEA, 2011).

O equilíbrio de compra se dá pela divisão da receita oriunda da venda das meia-carcaças, pelo peso de carcaça fria, em quilogramas ou em arrobas. Para exemplificar, a receita de $\mathrm{R} \$ 1.401,13$ da venda das meias-carcaças dos animais jovens e leves significa que o frigorífico obtém um equilíbrio na compra se pagar R \$6,22 / kg ou R \$ 93,30 / @. Caso consiga comprar por menos, está obtendo margem positiva, caso precise pagar mais, estará obtendo margem negativa.

Observa-se que se obtém uma diferença de receita da venda de cortes de $10,06 \%$ entre animais jovens com carcaças pesadas em relação aos animais com carcaças leves, mas a diferença no preço do ponto de equilíbrio de aquisição do animal gordo é de 7,40\% favorável aos animais leves. Isso se deve porque os $\mathrm{R} \$ 1.542,12$ gerados com uma carcaça pesada de animal jovem precisa remunerar $o$ produtor em $273 \mathrm{~kg}$ de carcaça, ao passo que os $\mathrm{R} \$$ $1.401,13$ gerados na receita da carcaça leve precisa remunerar ao produtor apenas $230 \mathrm{~kg}$ de carcaça $(15,33 @)$.

Obviamente que este trabalho não discute um provável maior custo de industrialização das carcaças mais pesadas, que poderia reduzir a diferença do preço de equilíbrio, como também não é considerado que uma carcaça de um animal mais pesado gera maior rendimento de componentes nãocarcaça, os quais representam considerável receita para a indústria frigorífica, ajudando a viabilizar o 
processo de abate e processamento. Isso é mais evidente ao passo que a receita com componentes não-carcaça acompanha o peso de carcaça e o custo industrial não cresce de forma proporcional ao aumento desse peso. Assim, pode-se inferir neste trabalho que os animais mais pesados viabilizam uma remuneração de, no mínimo 7,40\% a menos na aquisição do boi gordo, exceto pelo fato de gerarem mais receitas de componentes não-carcaça (PASCOAL et al., 2011).

Esse mesmo raciocínio, entretanto, toma efeitos diferentes quando se comparam animais adultos com os animais jovens e com carcaças leves. A diferença na receita da venda dos cortes primários atinge apenas 3,57\%, mas o preço do ponto de equilíbrio pode ser de até $9,81 \%$ a mais para os animais jovens.

A razão para a inversão dos preços dos pontos de equilíbrio pode ser verificada na Tabela 5 . Embora não tenha ocorrido diferença no rendimento de traseiro especial entre os grupos de carcaças estudados, as carcaças dos animais jovens, embora leves $(230 \mathrm{~kg})$, geram uma receita com a venda de um único traseiro especial de $\mathrm{R} \$ 415,69$. Já uma carcaça de um animal adulto com $264 \mathrm{~kg}$, gera uma receita com a venda de um traseiro especial de $R \$$ 421,51 , menos que $\mathrm{R} \$ 6,00$ de diferença. A diferença na receita com a venda de um único dianteiro é de $\mathrm{R} \$ 16,00$ e de uma ponta-de-agulha de aproximadamente $\mathrm{R} \$ 3,00$.

Se for considerado que $\mathrm{R} \$ 7,28$ é a remuneração do quilograma do traseiro especial e R \$ 4,85 a média da remuneração da ponta-de-agulha e do dianteiro, a diferença atinge 50,10\% de preço. Assim, se considerado que o consumidor final é o agente que remunera toda a cadeia produtiva de qualquer produto, ao exemplo da avicultura, que trabalhou para aumentar os rendimentos de peito e coxas dos frangos, as pesquisas em melhoramento genético em bovinos de corte deveriam buscar o aumentodos percentuais de traseiro especial dos animais, desde que atendidos os graus de acabamento mínimos exigidos pelos frigoríficos.

$\mathrm{O}$ fato de os animais serem inteiros pode ter afetado o desenvolvimento do traseiro dos animais mais erados (adultos), já que este é um fator relacionado à não castração dos animais e, com o avanço da idade, espera-se que os animais inteiros aumentem o dimorfismo sexual (ZHOU et al., 2011) e, com isso, a percentagem de dianteiro em relação ao traseiro especial de animais mais jovens.

Neste trabalho, não foram discutidos os fatores relacionados à qualidade da carne, tão bem explorados em outras pesquisas que trataram exclusivamente do aspecto técnico da redução da qualidade da carne com o avanço da idade de abate dos animais e aspectos de qualidade intrínseca do produto carne bovina (LANARI et al., 2002; NELSON et al., 2004). Nesse sentido, finalizando as considerações sobre avaliação econômica dos quatro grupos de carcaças estudadas, as pesquisas precisam atender à demandados frigoríficos de animais superjovens ou jovens, direcionando os estudos para o melhoramento genético para precocidade ao acabamento, para o uso de animais inteiros e seu maior crescimento em relação aos castrados, e para a qualidade da dieta, pois a redução da idade de abate passa pela melhoria da alimentação dos animais (CAÑAS et al., 1974). Assim, podem-se propiciar alterações no peso de abate que afetam as características da carcaça e da carne, principalmente aquelas ligadas ao crescimento da carcaça, em especial quanto à deposição de gordura. Esses efeitos estão diretamente relacionados ao nível energético da alimentação oferecida aos animais e, dessa forma, relacionados à lucratividade da terminação dos animais para o produtor e, consequentemente, para a indústria frigorífica, que pode melhor remunerar o produtor, segmento responsável pelo processo de produção de matéria prima.

Animais abatidos com peso inferior a 16@ de carcaça quente $(240 \mathrm{~kg})$, em geral, são penalizados no preço pelos frigoríficos nas regiões Norte e Centro-Oeste. Diante desse cenário, considerando apenas a comercialização dos cortes primários, os frigoríficos podem ter apenas como vantagem a venda dos componentes não-carcaça, que possuem produção maior nos animais mais pesados. No entanto, para o produtor, a elevação do peso de abate não apresenta vantagem aparente, à medida que a eficiência alimentar decresce com o avanço do período de terminação e do peso de abate dos animais. Além disso, o consumidor tem preferido cortes porcionados, de mais fácil preparo e de menor custo por peça ou porção.

No caso, não deve ser considerada a interferência da idade dos animais na maciez da carne, pois o debate se refere aos animais com diferentes pesos, três grupos abatidos com a mesma idade, com variação no grau de acabamento. Por outro lado, o maior grau de acabamento pode se refletir no marmoreio da carne, o que não foi verificado na presente pesquisa (Tabela 2), em função da alta variação dessa característica dentro dos grupos estudados, ilustrada pelo CV de $54,45 \%$.

\section{CONCLUSÕES}

Animais Nelore, abatidos com quatro ou seis dentes, possuem acabamento, pesos de carcaças similares e rendimentos de cortes comerciais comparáveis aos animais jovens, independente do 
peso de carcaça destes últimos.

Não há diferença no rendimento de carcaça e percentagens de osso, músculo e gordura entre animais jovens, de três pesos de carcaça distintos, e animais adultos.

Em função da maior receita com a venda de traseiro especial oriundo de carcaças leves, o preço de equilíbrio na aquisição do boi gordo que pode ser ofertado pelo frigorífico ao produtor, pode oscilar entre 7 e $10 \%$, se desconsiderados os rendimentos de componentes não carcaça e os custos industriais.

\section{REFERÊNCIAS}

ALBERTI, P.; PANEA, B.; SAÑUDO, C.; OLLETA, J. L.; RIPOLL, G.; ERTBJERG, P.; CHRISTENSEN, M.; GIGLI, S.; FAILLA, S.; CONCETTI, S.; HOCQUETTE, J. F.; JAILLER, R.; RUDEL, S.; RENAND, G.; NUTE, G. R.; RICHARDSON, R. I.; WILLIAMS, J. L. Live weight, body size and carcass characteristics of young bulls of fifteen European breeds. Livestock Science, v. 114, n. 1, p. 19-30, 2008.

BRASIL. Ministério da Agricultura, Pecuária e Abastecimento. Sistema Brasileiro de Classificação de Carcaças Bovinas. In: BRASIL. Ministério da Agricultura, Pecuária e Abastecimento. Instrução normativa N. 9 de 04 de maio de 2004. Diário Oficial da União, ano 141, n. 85, seção 1, p. 3, 2004.

BUENO, M. S.; CUNHA, E. A. da; SANTOS, L. E. dos; RODA, D. S.; LEINZ, F. F. Características de carcaça de cordeiros Suffolk abatidos em diferentes idades. Revista Brasileira de Zootecnia, v. 29, n. 6, p. 1803-1810, 2000.

CAMARGO, A. M.; RODRIGUES, V. C.; SOUSA, J. C. D.; MORENZ, M. J. F.; SILVA, J. C. G.; CABRAL NETO, O.; RAMALHO, R. O. S.; RAMOS, K. C. B. T. Características da carcaça de novilhas $1 / 2$ guzerá x 1/4 simbrasil $\mathrm{x} 1 / 4$ nelore, terminadas em confinamento e abatidas com diferentes pesos. Boletim da Indústria Animal, v.65, n.3, p.175-182, 2008.

CAÑAS, C. R.; GASTÓ, C. J. Costo de cosecha y eficiencia de producción em ecosistemasganaderos. Ciencia e Investigación Agrária, v. 1, p. 179-185, 1974.

CEPEA. Centro de Estudos Avançados em Economia Aplicada - ESALQ/USP. Agromensal CEPEA/ESALQ: informações de mercado; referência 06/11. Disponível em http://www.cepea.esalq.usp.br/agromensal/2011/06 junho /Pecuaria.htm. Acessado em 24/06/2011.

JEREZ-TIMAURE, N.; HUERTA-LEIDENZ, N. Effects of breed type and supplementation during grazing on carcass traits and meat quality of bulls fattened on improved savannah. Livestock Science, v.121, n.2-3, p.219-226, 2009.

KUSS, F.; LÓPEZ, J.; BARCELLOS, J. O. J.; RESTLE, J.; MOLETTA, J. L.; PEROTTO, D. Características da carcaça de novilhos não-castrados ou castrados terminados em confinamento e abatidos aos 16 ou 26 meses de idade. Revista Brasileira de Zootecnia, v. 38, n. 3, p. 515-522, 2009.

LANARI, M. C.; BREWSTER, M.; YANG, A.; TUME, R. K. Pasture and grain finishing affect the color stability of beef. Journal of Food Science, v. 67, n. 7, p. 24672473, 2002.

MALDONADO, F.; QUEIROZ, A. C.; ALLEONI, G. F.; RESENDE, F. D.; LEME, P.R.; BOIN, C.; NARDON, R. F.; DEMARCHI, J. J. A. A.; OLIVEIRA, R. V. Composição física da carcaça e rendimento dos cortes comerciais de bovinos de dois grupos genéticos abatidos com diferentes pesos. Boletim da Indústria Animal, v.64, n.2, p.123-130, 2007.

MARCONDES, M. I.;TEDESCHI, L. O.; VALADARES FILHO, S. C.; CHIZZOTTI, M. L. Prediction of physical and chemical body compositions of purebred and crossbred Nellore cattle using the composition of a rib section. Journal of Animal Science, v.90, n.4, p.12801290, 2012.

MC CURDY,M. P.; KREHBIEL,C. R.; HORN,G. W.; LANCASTER,P. A.; WAGNER, J. J. Effects of winter growing program on visceral organ mass, composition, and oxygen consumption ofbeefsteers during growing and finishing. Journal of Animal Science, v.88, n.4, p.15541563, 2010.

MÜLLER, L. Normas para avaliação de carcaças e concurso de carcaças de novilhos. 2. ed. Santa Maria: Universidade Federal de Santa Maria, 1987. 31 p. (Departamento de Zootecnia, Boletim Técnico, 1).

MULLER, L. Técnicas para determinar la composición de la canal. Guadalajara: Memoria de la Asociación Latinoamericana de Producción Animal, 1973. 75 p.

NELSON, M. L.; MARKS,D. J.; BUSBOOM,J. R.; CRONRATH, J. D.; FALEN, L. Effects of supplemental fat on growth performance and quality of beef from steers fed barley-potato product finishing diets: I. Feedlot performance, carcass traits, appearance, water binding, retail storage, and palatability attributes. Journal of Animal Science, v.82, n.11, p.3600-3610, 2004.

PACHECO, P. S.; SILVA, J. H. S. da; RESTLE, J.; ARBOITTE, M. Z.; BRONDANI, I. L.; ALVES FILHO, D. C.; FREITAS, A. K. de. Características quantitativas da carcaça de novilhos jovens e superjovens de diferentes grupos genéticos. Revista Brasileira de Zootecnia, v.34, n.5, p.1666-1677, 2005.

PASCOAL, L. L.; VAZ, F. N.; VAZ, R. Z.; RESTLE, J.; PACHECO, P.S.; SANTOS, J.P.A. Relações comerciais entre produtor, indústria e varejo e as implicações na diferenciação e precificação de carne e produtos bovinos não-carcaça. Revista Brasileira de Zootecnia, v.40, p.8292, 2011 (suplemento especial).

RIBEIRO, F. G.; LEME, P. R.; BULLE, M. L. M.; LIMA, C. G. de; SILVA, S. L. e; PEREIRA, A. S. C.; LANNA, D. P. D.Características da carcaça e qualidade da carne de tourinhos alimentados com dietas de alta energia. Revista Brasileira de Zootecnia, v.31, n.2, p.749-756, 2002. 
ROBERTS, A. J.; PAISLEY, S. I.; GEARY, T. W.; Holandesa alimentados com dietas contendo diferentes GRINGS, E. E.; WATERMAN, R. C.; MACNEIL, M. D. níveis de concentrado. Revista Brasileira de Zootecnia, Effects of restricted feeding of beef heifers during the postweaning period on growth, efficiency, and ultrasound carcass characteristics. Journal of Animal Science, v.85, n.10, p.2740-2745, 2007.

v. 28 , n. 1, p. 883-888, 1999.

SIGNORETTI, R. D.; SAMPAIO, R. L.; RESENDE, F. D.; COAN, R. M.; REIS, R. A.; ALLEONI, G. F.; FARIA, M. H.; SIQUEIRA, G. R.; MIGUEL, F. B. Ganho RODRIGUES, K. K. N. L.; ROSSI JÚNIOR, P.; MOLETTA, J. L.; MURARO, G. B. Avaliação do desempenho de bovinos mestiços Purunã, alimentados com diferentes níveis de energia. Boletim da Indústria Animal, v.64, n.3, p.241-247, 2007.

de peso vivo diário, conversão alimentar e características de carcaça de novilhos da raça Nelore, confinados e alimentados com dietas baseadas em silagens de capim marandu ou de milho. Boletim da Indústria Animal, v. 65 , n. 1, p. 71-82, 2008.

SAS - STATISTICAL ANALYSIS SYSTEM. SAS ZHOU, Z.; GAO, X.; LI, J.; CHEN, J.; XU, S. Effect of System for Windows. Cary: SAS Institute Inc., v. 8.0, castration on carcass quality and differential gene 1999. expression of longissimus muscle between steer and bull. SIGNORETTI, R. D.; ARAUJO, G. G. L.; SILVA, J. F. C. Composição física da carcaça de bezerros da raça

Molecular Biology Reports,v.38, n. 8, p.5307-5312, 2011.

Protocolado em: 21 nov. 2012. Aceito em 21 fev. 2013. 